\title{
Impact of Transportation on Carbon Dioxide Emissions from Locally vs. Non-locally Sourced Food
}

\author{
Bradley Striebig ${ }^{a^{*}}$, Eric Smitts ${ }^{\text {a, }}$, Samuel Morton ${ }^{\text {a }}$ \\ ${ }^{a}$ James Madison University, 800 Carrier Drive MSC 4113, Harrisonburg, VA 22801 USA
}

\begin{abstract}
The concentration of carbon dioxide in the atmosphere continues to rise, and the global food system is a significant contributor that often gets overlooked when it comes to solving the problem. In this study, emissions related to food transportation were studied to determine what impact getting local food instead of non-local food could have on the overall emissions of the food system. The dining service at the university utilizes local food to varying extents when it is in season, and a life cycle assessment (LCA) was done on lettuce, tomatoes, strawberries, and chicken to compare the emissions associated with the production of these foods. The transport-oriented GREET software was used for the LCA along with information from the sustainability coordinator at the university itself to get results. Given a lack of publicly available data regarding crop cultivation in certain areas of the U.S., some information had to be obtained from databases in Europe, but results suggest that produce coming from the west coast to the Virginia campus can have four to five times the emissions associated with production, and produce from Florida can have roughly twice as many emissions associated with production. There is a relatively low number of LCAs done in America to compare this data to, but it somewhat fits in with many European studies. Some LCAs do not factor in transportation processes, but my results suggest that any American studies should factor in transportation since it can contribute greatly to the overall footprint of products. The current available software for LCAs lacks consistency between programs, all having different strengths and weaknesses, and needs to be improved for quality results in the future.
\end{abstract}

\section{Keywords:}

LCA;

GREET;

Food;

Carbon Dioxide;

Green House Gas.

Article History:

Received: 11 March 2019

Accepted: 05 July 2019

\section{1- Introduction}

\section{1-1- Sustainability in Food Delivery}

The push for sustainability and a "greener" America in the food industry has been almost entirely carried out by the American public rather than legislative pressures. Ivanova et al. report that food has a 40-70\% global impact on land and water resources, with those impacts generally being proportionate to expenditure [1]. As a result, non-governmental organizations (NGOs) play a role in informing the public of what is in their food and how it was grown or raised. Food companies rely on third party certifications to inform consumers about food standards and criteria regarding the products' growth and production. The focus of such standards, however, is more for marketing and product differentiation. Most of the certifications seen on products in the grocery store relate to the conditions in which the food was grown or raised, such as organic and fair trade certifications. Many of these are unrelated to food transportation and do not take into account where the food comes from.

There are two main organizations directly associated with third party certifications related to carbon emissions of food and restaurant services, Food Service Technology and Green Restaurant Association (GRA). Food Service Technology (FST) is focused primarily on food service equipment. While they don't provide certifications, they do

\section{* CONTACT: Striebba@jmu.edu}

DOI: http://dx.doi.org/10.28991/esj-2019-01184

(C) 2019 by the authors. Licensee ESJ, Italy. This is an open access article under the terms and conditions of the Creative Commons Attribution (CC-BY) license (https://creativecommons.org/licenses/by/4.0/). 
provide energy efficiency information for the equipment used in restaurants. FST provide information on lighting and ventilation; FST also provides cost calculators for things like life cycles and water leaks (among others), and free seminars on topics of sustainability in the food service industry [2]. The second major organization in the U.S. is the GRA, which awards certifications of various degrees ranging from 1 star to 4 star ratings based on various indicators. There are guidelines and requirements in water efficiency, waste reduction and recycling, sustainable durable goods and building materials, sustainable food, energy, reusable and environmentally preferable disposables, and chemical and pollution reduction. Guidelines specific to food transport and farming practices fall under the sustainable food category, which takes into account where the food comes from and how it is grown/raised, which further relies on other third party certifications. A percentage of food ingredients must come from local sources, which are defined as food transported 100 miles or less from farm to plate, and regional sources, with a range of 300 miles from farm to plate. Seafood is assessed slightly differently and in order for the restaurant to gain approval from the GRA; the harvesting must be deemed sustainable by GRA [3]. The GRA has the strongest presence in large metropolitan areas such as Boston, Chicago, or Los Angeles, but has certified restaurants or food services scattered all across the country.

There are many different certifications available from third parties regarding different aspects of food production. The U.S. Department of Agriculture (USDA) issues an organic certification to products grown using different practices promoting ecological balance and conservation of biodiversity while avoiding use of synthetic fertilizers, sewage sludge, irradiation, and genetic engineering [4]. The Food Alliance certifies products without artificial flavors, colors, or preservatives, without genetic modification, humane care for livestock, and verified chain traceability. All products must also be grown by a certified producer and packaged/prepared by a certified handler [5]. The Fair Trade certification goes out to products developed without the exploitation of workers and is especially important for products coming from underdeveloped countries [6]. Rainforest Alliance certifications are awarded to those companies and products working towards sustainable agriculture, forestry, and tourism in an effort to combat climate change and provide environmental education [7]. In regards to the treatment of animals, both the Certified Humane Raised and Handled and Animal Welfare Approved organizations offer certifications [8], with the Animal Welfare Approved certifications being stricter and awarded only to family farmers [9]. Salmon Safe is limited to the Pacific Northwest but requires farms to meet standards for protection and restoration of instream habitats and riparian vegetation, water use management, erosion prevention, and biological diversity among other things [10]. Marine Stewardship Council offers certifications to fisheries based on performance indicators such as maintaining sustainable fish stocks and minimizing environmental impacts. Protected Harvest sets standards for how food crops are grown depending on the specific food, along with which bioregion it is being grown in, recognizing the requirements vary greatly by region [11]. These are only some of the more popular certifications available to food and can play a role in other NGO certifications, as seen in the GRA which rewards restaurants whose food contains USDA Organic ingredients, but do not necessarily apply to larger food consuming industries like college campuses.

\section{1-2-Sustainability in Food Delivery}

The current structure of the global economy makes it cheaper in many cases to import food from across the country or across the world. The goal of this project is to learn to what extent XU dining food acquisition is sustainable. With the knowledge that XXX University (XU) got some of its food from local sources when in season and from across the country when out of season, a comparison between the two systems was made to better understand the effects of each. Given the large transportation distance, it was hypothesized that the total emissions would show a significant difference when coming from California or Florida compared to local farms.

\section{1-3-Life Cycle Analysis of Food Delivery}

There are numerous LCAs done on various crops but few factor in transportation and even fewer compare local and non-local food heading to the same destination. The focus of this study was to compare the emissions related to transportation, with the understanding transportation often played a limited role in overall emissions related to food production. A part of this study was focused on determining at what point transportation is no longer inconsequential. This is similar to the study mentioned earlier by Coley et al. that determined at what point a food delivery system could be more efficient than having individuals drive to the grocery store [12]. In other cases, transportation is lumped into a post-farm category and includes other processes such as storage and packaging, therefore not specifically addressing transportation. The objective of this study is to quantify the emissions from the transportation of tomatoes, lettuce, strawberries, and chicken to $\mathrm{XU}$, focusing on the differences in both emissions and water usage between local and nonlocal sources.

Argonne National Laboratory is a science and engineering research center working on issues related to clean energy, environment, technology, and national security. With sponsorship from the U.S. Department of Energy's Office of Energy Efficiency, they created the life-cycle model called GREET (Greenhouse gases, Regulated Emissions, and Energy use in Transportation). By incorporating different fuel pathways and vehicle technologies, it is designed to evaluate different vehicle and fuel combinations in the context of a life cycle assessment (LCA) [13]. As the name suggests it is most suited for analyses focused on transportations, especially those comparing various forms of transportation. 
While differences in inputs were known to some extent, the goal of the study was largely based on transportation. Because the food products are not a fuel, the process had to be created within the program, relying on a somewhat limited knowledge of the inputs required in cultivation and processing. Additionally, infrastructure such as the buildings chickens were raised in and greenhouses fell beyond the scope of the GREET software. These limitations are important when comparing results to other LCAs that do take these things into account, but were not the focus of this assessment. Leach et al. describe how institutions may use carbon and nitrogen footprints to track the institutions environmental impact, including food management scenarios [14]. Paul et al. described how greenhouse gas emissions could be estimated from a variety of foods produced locally within households in Rwanda in order to help meet home food shortages and the relationship between food production and GHG emissions. Paul et al. found that soils and crop planting had the most promising low emitting sources of local food, while meat and livestock production yielded high GHG emission [15].

Many LCAs on tomatoes done are regarding those grown in greenhouses, which have a much larger indirect footprint due to the emissions related to construction and heating/lighting of the structure. It is worth noting that the location of the greenhouses plays an important role in their energy consumption, with colder climates requiring greater energy to maintain a suitable temperature for growing conditions [16]. The same study showed the biggest contributor to global warming potential was the greenhouse structure itself and the energy put into its production. This study however, did not look at any post-production stages of the tomatoes and therefore transportation was not considered. Besides the structure, auxiliary equipment and the production and application of fertilizers were the other main contributors to global warming potential of tomato production in the greenhouse [16]. A study that included storage and transport concluded that imports from Israel to Sweden resulted in lower emissions than local greenhouse production in the UK [17]. However, in addition to variations in location and cultivation methods that make food production comparisons difficult, greenhouses also vary depending on type and construction of the structure. They also reported that certain packaging might reduce emissions compared to the classic box and cold chain distribution pathway [17]. In total, tomato production is greatly dependent on where it is grown and the methods used. Values range greatly, with less than $300 \mathrm{~g} \mathrm{CO}_{2} e$ emissions per $\mathrm{kg}$ of tomato in the study done by Torrellas et al. and nearly $1 \mathrm{~kg} \mathrm{CO}_{2} e$ per $\mathrm{kg}$ of greenhouse-grown tomato in an Italian study done in 2010 that included transportation, packaging, and waste [18]. The different LCAs show that even when done thoroughly and in-depth, the estimated emissions can vary greatly.

Production of strawberries varies greatly depending on where they are grown. A study was done in Iran comparing open field strawberries and those grown in a greenhouse. In the study, transportation and post-harvest processes were not taken into account, only studying cradle to farm-gate. The yield per hectare was significantly lower in the open-field production but cost much less, with an overall benefit-cost ratio over four times higher than greenhouse growing [19]. The greenhouse used plastics and a greater diversity of fertilizers and pesticides, but the open field used a greater amount of chemicals on the crops overall while requiring just over half the amount of labor and almost no electricity resulting in a total global warming potential roughly $15 \%$ lower when compared to greenhouse production [19]. It should be noted that the area used for the open field study in Iran was especially well-suited for strawberry growth, meaning other areas may not have as substantial difference a between the two methods. Another study that included strawberries was done in Australia, also focusing mostly on pre-farm and farming activities, only including some transportation in the analysis. This study cited agricultural machinery operation as the main contributor to emissions (58\%) with the use of fertilizers $(23 \%)$ and electricity $(12 \%)$ rounding out the significant sources of $\mathrm{CO}_{2}[20]$. While not all aspects of transportation were included in the analysis, transportation was shown to contribute only $2 \%$ of $\mathrm{CO}_{2}$ equivalents $\left(\mathrm{CO}_{2} e\right) / \mathrm{KJ}[20]$. The use of KJ as a functional unit is uncommon in LCAs but was done in this case to make the data comparable with other crops (lettuce and mushrooms) in the study. This data suggests that growing strawberries in greenhouses contributes more emissions than open field production, but requires much less space and productivity is less dependent on climate.

Like the other crops mentioned, growing lettuce produces varying amounts of emissions based on many different factors. Hall et al. paper reported on industrial production compared to civic production, of which they defined as urban or residential-rural areas in 2014. For lettuce production, the civic producers used less water and one of them produced far fewer emissions $\left(0.08 \mathrm{~kg} \mathrm{CO}_{2} e\right.$ per kg lettuce) than the other civic producer $\left(0.25 \mathrm{~kg} \mathrm{CO}_{2} e\right.$ per kg lettuce $)$ and the industrial producer $\left(0.32 \mathrm{~kg} \mathrm{CO}_{2} e\right.$ per kg lettuce) by using home chicken manure instead of fertilizers and minimized car transport [21]. Fertilizers require fossil fuels to create, which is partly responsible for the increased footprint of large scale farming activities compared to small-scale agriculture. The study included transportation in its analysis and cited it as part of the main emission producers (fuel for both tractor and transport), ahead of fertilizers [21]. However, the study concluded that the main emission contributions came during the growing phase, so fuel for transport may be a small portion of that. Additionally, the civic suppliers in the study saw educational value in their practices and enjoyed demonstrating the potential of backyard and community gardens, an added value that cannot be quantified. Gunady et al. evaluated lettuce and cited agricultural machinery operation and electricity as the two largest impact factors, followed by nitrogen fertilizers [20]. The transportation phase accounted for 7\% of emissions per KJ of energy in this study but that could be partly attributed to the lack of caloric value in lettuce, which requires over $30 \%$ more mass to equal the energy of strawberries. While growing conditions in Australia may not translate to all locations, these studies are important in showing that when farming significant influence life cycle emissions. 
Chicken is different than the other crops mentioned so far because it has additional processing steps and requires additional packaging and refrigeration. The growing of the chickens is still the most energy intensive [21, 22], but according to a study done in Finland on broiler chickens, the housing, packaging, and slaughtering rank as the third, fourth, and fifth most energy-demanding processes respectively [22]. In terms of emissions and global warming potential, slaughtering and packaging are less impactful but broiler housing creates roughly $80 \%$ of the $\mathrm{CO}_{2} e$ as the growing of chickens, with all other processes falling near or below $20 \%$ of growing the chickens [22]. Hall et al. compared small-scale versus industrial production of chicken. However, unlike lettuce production, the chicken industry turned out to be much more efficient in terms of emissions and land use, while having similar water consumption as one small-scale producer and nearly half the consumption of the other [21]. Chicken farms hold so many chickens and are so efficient that practices like feeding small-scale chickens food scraps and using rain water instead of well water don't reduce emissions enough to make the practices significantly reduce impacts.

A study done in Iowa took an in-depth look at the potential $\mathrm{CO}_{2}$ emission reductions that are possible by utilizing non-conventional food transportation. It looked at a total of 28 different food items and defined three distinct food systems and their transportation methods. The conventional food system was simplified to only national sources, not international, and utilized large semi-trailer trucks for transport. An Iowa-based regional system was hypothesized and modeled after an existing regional infrastructure involving brokers and distributors to deliver Iowa-grown food from small and midsize farms to various markets such as supermarkets and restaurants. This system would use large semitrailer trucks and midsized trucks over an estimated 82-mile average distance from farm to sale. A local system was modeled on the idea of farmers directly interacting with consumers and retailers through the use of light-duty vehicles that would run on gasoline (as opposed to diesel) and travel an estimated 38 miles from farm to sale on average. The results showed that the regional system was most efficient and greenhouse gas emissions could be reduced by 7 million pounds [23]. Although there are significant reductions with the local system as well, the smaller vehicles have to make a lot more trips in order to meet the consumption demands. Based purely on the transportation phase, Pirog et al. concluded transportation impacts could be reduced through centralized and localized planning, but they did not factor in the potential increase in production inputs in Iowa compared to other areas with warmer climates or the seasonality of crops grown in Iowa.

\section{2- Approach to Life Cycle Analysis of Food Delivery for University Dinning Services}

GREET was used to conduct an LCA study on the difference between the carbon footprint of local and non-local food. While other software is out there, such as SimaPro and ECO-it from PRé Consultants, GaBi from PE-International, and IDEMAT from Delft University of technology (Striebig et al. 2015), GREET was chosen because it is transportationoriented, which is the main difference between local and non-local food in this study. The chosen foods are some of the most common foods used by the university dining service and therefore will have a larger impact on the overall emissions emitted. The study focused on tomatoes, lettuce, strawberries, and chicken. Previous knowledge that the university got some of these foods specifically from local sources when in season and available aided in the decision. For the basis of the analysis the functional unit was defined as $100 \mathrm{~kg}$ of each food item. While the use of KJ as a functional unit to compare different foods can be useful, a functional unit using mass was chosen in an effort to make this study more comparable with other LCAs, most of which use a mass as well.

This study has its limitations. Data came from various sources and in the case of inputs is not necessarily specific to the region from which foods are actually coming. The study therefore does not always demonstrate tradeoffs in local food production grown under less than optimal conditions and imported food grown in optimal or close to optimal conditions as was the original intent of the project, but still provides useful data about transportation emissions. The use of storage facilities and distribution centers for long distance transport was beyond the scope of this study based on the information available. Similarly, the variation in transport vehicles is acknowledged but specific information was unavailable and therefore generalized for simplification. Although not part of the information used in the study, GREET does not include temperature-controlled vehicles as an option for transportation. Some of the inputs such as electricity and plastic for packaging are rough estimations at best based both the Danish Government information for chicken and Ecoinvent data from a group of Swiss institutes within the SimaPro database since I was unable to find any specific numbers. The study is limited in the sense that it highlights only the transportation phase and assumptions were made in other aspects of the food chain.

Publicly available data regarding LCAs for many food products, even for the common ones used in this analysis, is sparse. Information specific to XU and its dining service came from Charles Leventry, the sustainability coordinator on campus. He provided information about where these specific foods come from, how it gets there, and to some extent the proportions of local food the dining service uses. Inputs used to grow these items came from a variety of sources. Information regarding fertilizer inputs came from the USDA and all other inputs were taken from the Danish Government, within the SimaPro database [24-27]. From this source there was specific information on tomatoes and chicken based on data from Europe. General fruit and vegetable farming was also within the SimaPro database but was 
in a unit of measurement that did not make the data useful without knowledge of how much XU dining service spent on different food items. Since information regarding inputs for strawberry and lettuce growth could not be found, the tomato information was used as a substitute outside of fertilizer inputs.

Distances traveled by the vehicles was estimated using Google Maps. Local farms had addresses but non-local food was simply given a general area. Over half of the lettuce grown in California comes from Monterey County and there is a large strawberry grower in Salinas, CA, also in Monterey County, so distances were estimated from the city of Monterey itself [28]. Food production in Florida is common in the southern part of the state but not specific to one area like in California, so Belle Glade was used as a reference point and distances were approximated from there due to the large number of fields surrounding it on Google Earth and its roughly central location in Southern Florida. For Arizona production, Google Earth was used to find a large concentration of farms in the south-central area and distance was estimated based on where those farms were. While not precise, inaccuracies were likely inconsequential based on the overall distance between Arizona and XU campus. Dodd's Acres Farm was used as the source for local tomatoes approximately 130 miles from campus, Standard Produce Company was used as the local source for strawberries approximately 55 miles from campus, and Kirby Farms was used as the local source for lettuce approximately 130 miles from campus.

The GREET software is focused on emissions related to transportation, but the goods that are transported are also often related to fuels in some way. The database includes various fuels themselves such as gasoline and natural gas, but also includes resources used to create them and even components used to make electric batteries. Therefore, the food items used in my study first had to be created within the software using data from Charles, SimaPro, and the USDA. Farming processes were created and included inputs such as nitrogen and water per $100 \mathrm{~kg}$ of product. In order to determine the amount of chemicals used, data was found on yields to go with my USDA data on chemical applications. For example, tomato yields in Florida averaged $366 \mathrm{cwt}$ per acre in 2009 and inputs included $173 \mathrm{lbs}$. per acre of nitrogen, 0 phosphate, $302 \mathrm{lbs}$. per acre of potash, and $181 \mathrm{lbs}$. per acre of sulfur in 2014 resulting in $4.22 \mathrm{~g}$ of nitrogen, $7.37 \mathrm{~g}$ potash, and $4.42 \mathrm{~g}$ sulfur per $\mathrm{kg}$ of tomatoes respectively (Figure 1) [24-27]. A similar process was used for the other crops and locations. The USDA listed phosphorus, potash, and sulfur as inputs along with nitrogen, which were put into GREET as phosphoric acid, potassium oxide, and sulfuric acid respectively. Tomatoes were the only product found with yield information in Virginia (300 cwt/acre in 2009) but did not have chemical input data, so numbers from North Carolina were used to get a rough estimate of lbs./acre for fertilizer use in a relatively nearby area with similar climate and soil. Yields from 2009 were available for lettuce in California and Arizona along with Strawberries in California and Florida and were used with the 2014 data on chemical applications. For lettuce and strawberry local production, figures were not available from the USDA since overall production is minimal in the Virginia area. Chemical application was based on the "multi-state" figures in the USDA data and yields from the California data were used for the sake of simplicity.

\begin{tabular}{|c|c|c|c|c|c|}
\hline \multicolumn{6}{|c|}{ Drag and Drop Inputs below } \\
\hline \multicolumn{2}{|c|}{ Nitrogen } & \multicolumn{2}{|c|}{ Water } & \multicolumn{2}{|c|}{ Electricity } \\
\hline Quantity & $422 \mathrm{~g}$ & \multirow{3}{*}{$\begin{array}{l}\text { Quantity } \\
\text { Source }\end{array}$} & $2526.90 \mathrm{~kg}$ & \multirow{7}{*}{$\begin{array}{l}\text { Quantity } \\
\text { Source } \\
\text { Pathway Mix } \\
\end{array}$} & $109.80 \mathrm{MJ}$ \\
\hline Source & Pathway Mix & & Primary resource & & Single Pathway \\
\hline Pathway Mix & Pathway Mix: Nitrogen Ave. & & & & Pathway: Distributed U.S. \\
\hline \multicolumn{2}{|c|}{ Potassium Oxide } & \multicolumn{2}{|c|}{ Sulfuric Acid } & & \\
\hline Quantity & $737 \mathrm{~g}$ & Quantity & $442 \mathrm{~g}$ & & \\
\hline Source & Single Pathway & Source & Single Pathway & & \\
\hline Pathway Mix & Pathway: Potassium Oxide & Pathway Mix & Pathway: Sulfuric Acid Pro & & \\
\hline
\end{tabular}

Figure 1. Florida raised tomato inputs to the GREET model.

A transportation process was then created using a medium heavy-duty vehicle for local crop transport and heavy heavy-duty vehicles for the long range transport, creating separate processes for local and non-local transport (Figure 2). A pathway was then made connecting the farming process and the transportation process with the output being that crop or food item (Figure 3). When a crop was received from more than one non-local state, separate farming and transportation processes were made for each. For the chicken, a chicken raising process and a separate chicken butchering process were made and coincided with a transportation process bringing the output of processed chicken to XU campus. Upon completion of the pathway, the GREET program then provided emission outputs for the entire process. 


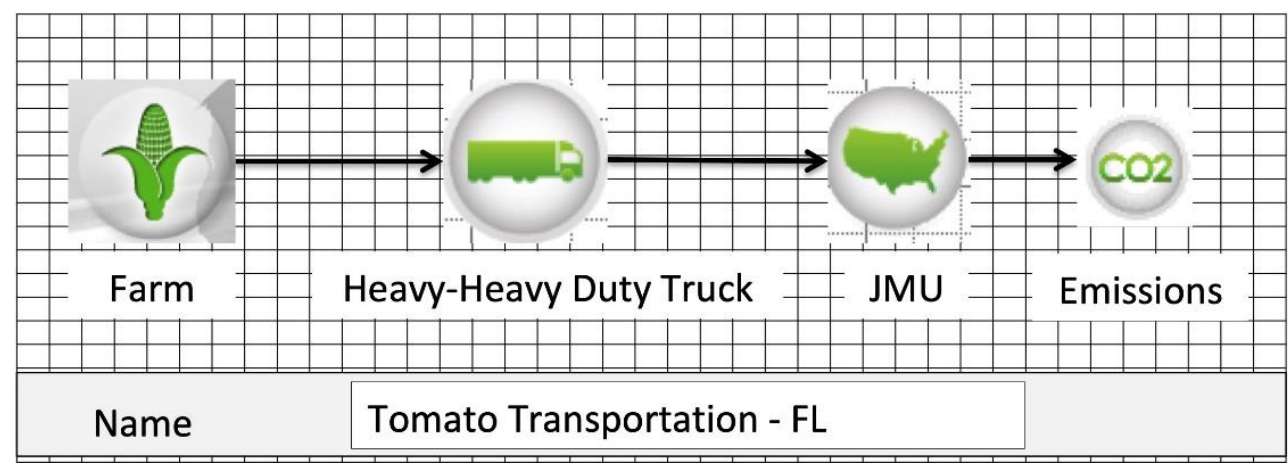

Figure 2. GREET-based transportation process for farm to dining services.

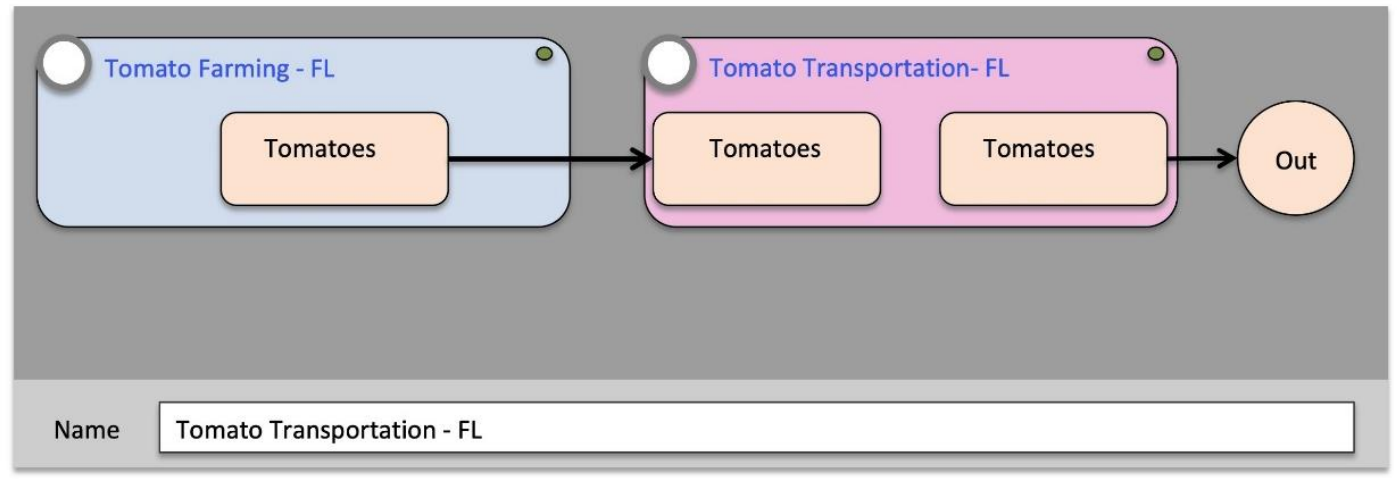

Figure 3. Florida raised tomato process for comparing $\mathrm{CO}_{2}(e)$ emissions from farm to dining services.

In order to get results, multiple assumptions had to be made. Inputs for growing tomatoes were assumed to be the same in Europe, where the data came from, as both Florida and the area surrounding Harrisonburg, Virginia. This assumption was made because of a lack of available data, not because it is necessarily believed to be true. Although a majority of lettuce comes from Monterey County in California and that county happens to also have a large strawberry supplier, XU strawberries and lettuce may not come from there, which would alter the distances traveled, though not a great deal most likely. The assumption was made that inputs for growing tomatoes is the same as inputs for growing lettuce and strawberries everywhere in the U.S. with the exception of fertilizers. Transportation was assumed to happen all in one trip without the use of storage facilities or distribution centers. This was again made because of a lack of information rather than believing it to be true. Due to the campus of XU being bisected by an interstate, it was assumed that there was no significant urban share to the transport miles involved in importing food. Crop production was assumed to take place in an open field rather than in a greenhouse. The vehicle payloads for crops were based off a study done on strawberry transportation, which stated 53-foot refrigerated trailers carried 29,568 lbs. of strawberries in corrugated containers and less in reusable plastic containers [29]. For simplicity, this was rounded to 15 tons and assumed that both tomatoes and lettuce would have the same payload since no transportation studies could be found with those specific crops. If the semi-trailers have an assumed max load of 19 tons as the Pirog study states, that represents a payload of roughly $79 \%$, which was then also applied to the medium heavy-duty vehicles used in local transportation, resulting in a payload of 5.5 tons based off of an assumed 7 ton max load. [23] Refrigerated vehicles are not available in GREET so although payloads of refrigerated semi-trailers were used, the emissions are based on non-climate controlled vehicles.

Due to the climate in Virginia, getting local crops requires them to be in season. Based on information from Charles, an estimated $60 \%$ of tomatoes, $30 \%$ of strawberries, and $10-15 \%$ of lettuce used by the dining services on campus come from local sources throughout the year. These numbers vary depending on local harvest conditions and availability and can come from a variety or combination of farms in the area ranging from 16 to 140 miles away. Tomatoes and sometimes strawberries are obtained from Florida which was an estimated 950 miles from campus. California was estimated to be 2,750 miles away and provides lettuce and the rest of non-local strawberries. Some lettuce also comes from Arizona, which was estimated to be 2,380 miles to campus. Approximately $13 \%$ of chicken meat and eggs come from local sources but again varies with seasonality and menu changes. A majority of egg purchases are met by a supplier in Lititz, PA, roughly 220 miles from campus. Due to the variety of suppliers and distributors used, other information regarding how and where the chickens are raised was unavailable in my limited survey.

The water and electricity inputs were the same for the three crops and based on the SimaPro database for tomato production. For $100 \mathrm{~kg}$ of product, $1.05 \mathrm{~m}^{3}$ of water and $109.8 \mathrm{MJ}$ of electricity were used. Nitrogen, phosphorus, potash, and sulfur inputs were taken from USDA information and can be seen in Table 1. Based on these inputs and the 
information regarding transportation, emission data was obtained from GREET. Chicken inputs included $55 \mathrm{kWh}$ of electricity, $67 \mathrm{~g}$ nitrogen, and $200 \mathrm{~kg}$ of corn for raising, and $60 \mathrm{kWh}$ electricity and $5 \mathrm{~kg}$ of plastic packaging to produce an estimated $90 \mathrm{~kg}$ of processed chicken from every $100 \mathrm{~kg}$ of chicken raised. Emissions results are given in Global Warming Potential (GWP), which the EPA uses as a label to compare emissions from different gases. It reflects how much energy the gaseous emissions will absorb over time compared to carbon dioxide, which has a GWP of 1 . Higher GWP values from other gases mean they absorb more energy over time and therefore cause a greater rise in the Earth's temperature over a set time period [30]. Most often a time period of 100 years is used, as is the case in emissions results from GREET.

Table 1. Inputs for crop production

\begin{tabular}{ccccccccc}
\hline & $\begin{array}{c}\text { Tomato - } \\
\text { Local }\end{array}$ & $\begin{array}{c}\text { Tomato - } \\
\text { FL }\end{array}$ & $\begin{array}{c}\text { Lettuce - } \\
\text { Local }\end{array}$ & $\begin{array}{c}\text { Lettuce - } \\
\text { CA }\end{array}$ & $\begin{array}{c}\text { Lettuce } \\
-\mathbf{A Z}\end{array}$ & $\begin{array}{c}\text { Strawberry - } \\
\text { Local }\end{array}$ & $\begin{array}{c}\text { Strawberry - } \\
\text { FL }\end{array}$ & $\begin{array}{c}\text { Strawberry - } \\
\text { CA }\end{array}$ \\
\hline Water (kg) & 2,527 & 2,527 & 2,527 & 2,527 & 2,527 & 2,527 & 2,527 & 2,527 \\
Electricity (MJ) & 110 & 110 & 110 & 110 & 110 & 110 & 110 & 110 \\
Nitrogen (g) & 298 & 422 & 454 & 418 & 617 & 125 & 240 & 142 \\
Phosphoric Acid (g) & 199 & - & 302 & 227 & 594 & 45 & 336 & 43 \\
Pot. Oxide (g) & 488 & 737 & - & 111 & - & - & 992 & 62 \\
Sulphuric Acid (g) & 77 & 442 & - & 65 & - & 22 & - & 21 \\
\hline
\end{tabular}

\section{3- Results and Analysis from GREET-based Transportation Model of Food Sources}

This study aimed to identify carbon emissions related to food transportation of the XU dining service, focusing the comparison of local and non-local tomatoes, lettuce, strawberries, and chicken. Transportation is often left out of food life cycle assessments (LCA), only partially included, or the emissions are assumed to be overall negligible, but the results from this GREET-based model suggests transportation emissions are not negligible in this particular food system.

Of the three produce items, lettuce from California had the highest emissions (103.99 kg/100 kg lettuce), followed closely by strawberries from California $(102.41 \mathrm{~kg} / 100 \mathrm{~kg}$ strawberries). Emissions per $100 \mathrm{~kg}$ of processed chicken equaled $197.55 \mathrm{~kg}$ using the only known location for chicken products made available (Lititz, PA). As seen below, $\mathrm{CO}_{2}$ emissions were very close to the GHG100 emissions for all of the produce items (4-6\% higher GHG100 emissions) whereas chicken production showed a significant difference between the two, with GHG100 emissions being $28 \%$ higher as shown in Figure 4.

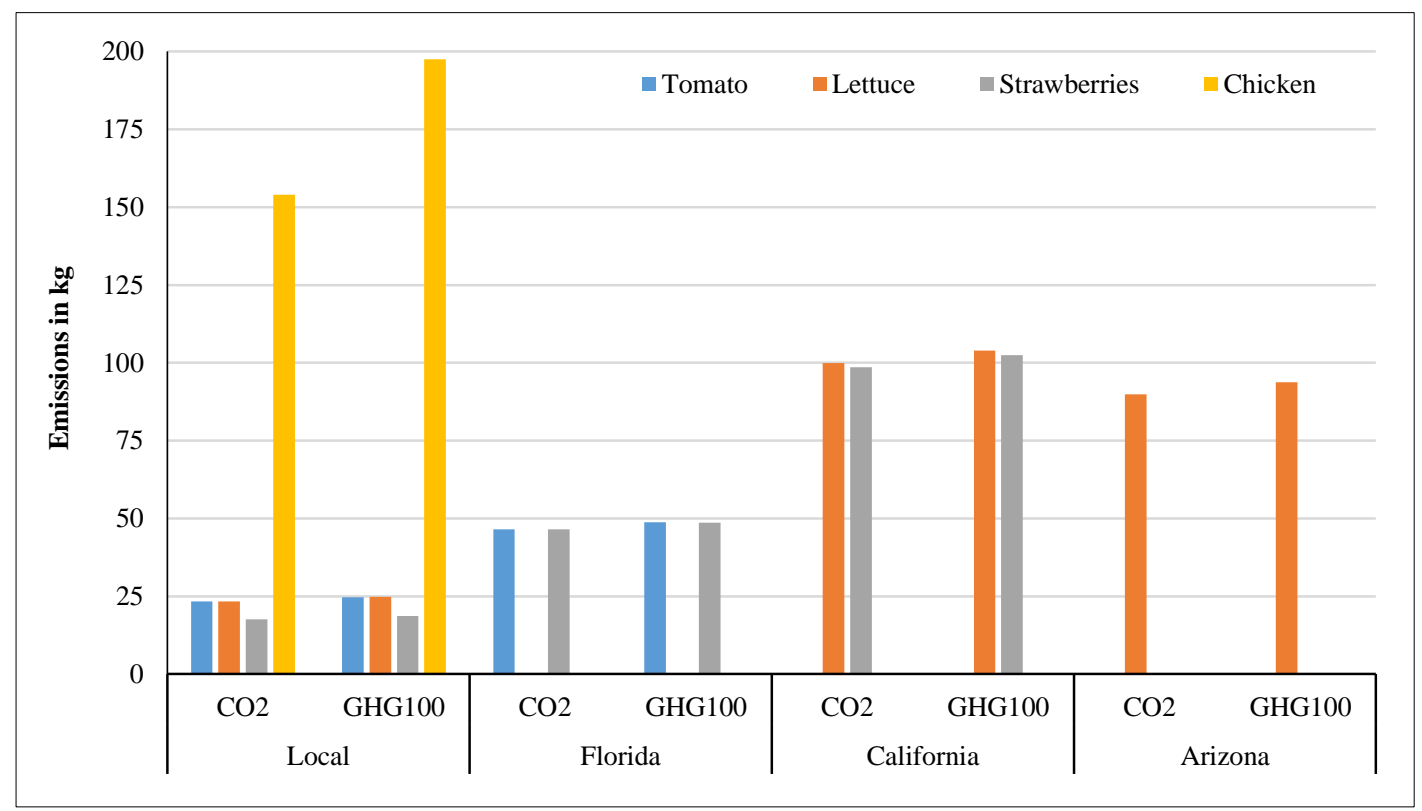

Figure 4. $\mathrm{CO}_{2}(e)$ transportation-related emissions for tomatoes, lettuce, strawberries and chicken.

It is worth noting that none of these items come from so far away that they need to be flown into the country. As shown earlier, air transport can release approximately six times the amount of $\mathrm{CO}_{2}$ as road transport [23]. Using only road transportation reduces the impact associated with the selected foods compared to other food items that get transported through the air. Despite an additional $390 \mathrm{~g}$ of chemicals per $100 \mathrm{~kg}$ of lettuce grown in Arizona, the relatively small savings in distance to XU of 370 miles was enough to result in a lower emissions output compared to lettuce from California. Similarly, chemical inputs in Florida for strawberry production were by far the highest of the 
three locations (Figure 5) but were not reflected in the overall emissions (Figure 6). Little information on where the dining service gets chicken was available but based on estimations for inputs it is highly likely that meat production creates a greater amount of $\mathrm{CO}_{2}$ emissions and a much greater amount of other greenhouse gases (Table 2). Chickens are often considered a carbon friendly meat product as well so other meats like beef would likely have an even greater impact.

Table 2. Emissions in $\mathrm{kg}$ per $100 \mathrm{~kg}$ of product

\begin{tabular}{c|cc|cc|cc|cc}
\hline \multirow{2}{*}{ Tomatoes } & \multicolumn{2}{|c|}{ Local } & \multicolumn{2}{c|}{ Florida } & \multicolumn{2}{c|}{ California } & \multicolumn{2}{c}{ Arizona } \\
\cline { 2 - 9 } & $\mathrm{CO}_{2}$ & $\mathrm{GWP}$ & $\mathrm{CO}_{2}$ & $\mathrm{GWP}$ & $\mathrm{CO}_{2}$ & $\mathrm{GWP}$ & $\mathrm{CO}_{2}$ & $\mathrm{GWP}$ \\
\cline { 2 - 9 } Lettuce & 23.38 & 24.74 & 46.57 & 48.82 & - & - & - & - \\
Strawberries & 23.33 & 24.79 & - & - & 99.96 & 103.99 & 89.94 & 93.81 \\
Chicken & 17.57 & 18.62 & 46.49 & 48.62 & 98.64 & 102.41 & - & - \\
\hline
\end{tabular}

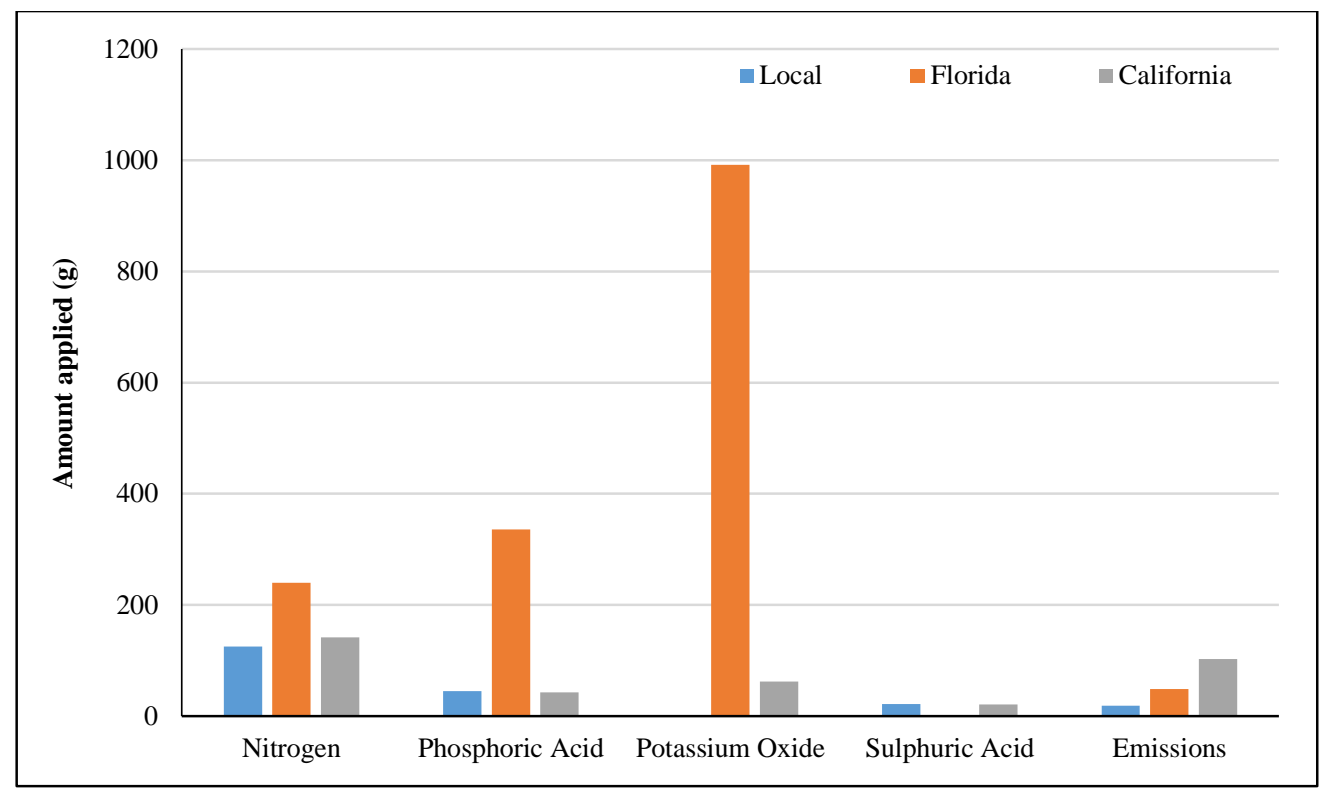

Figure 5. Chemical fertilizer use in strawberry production.

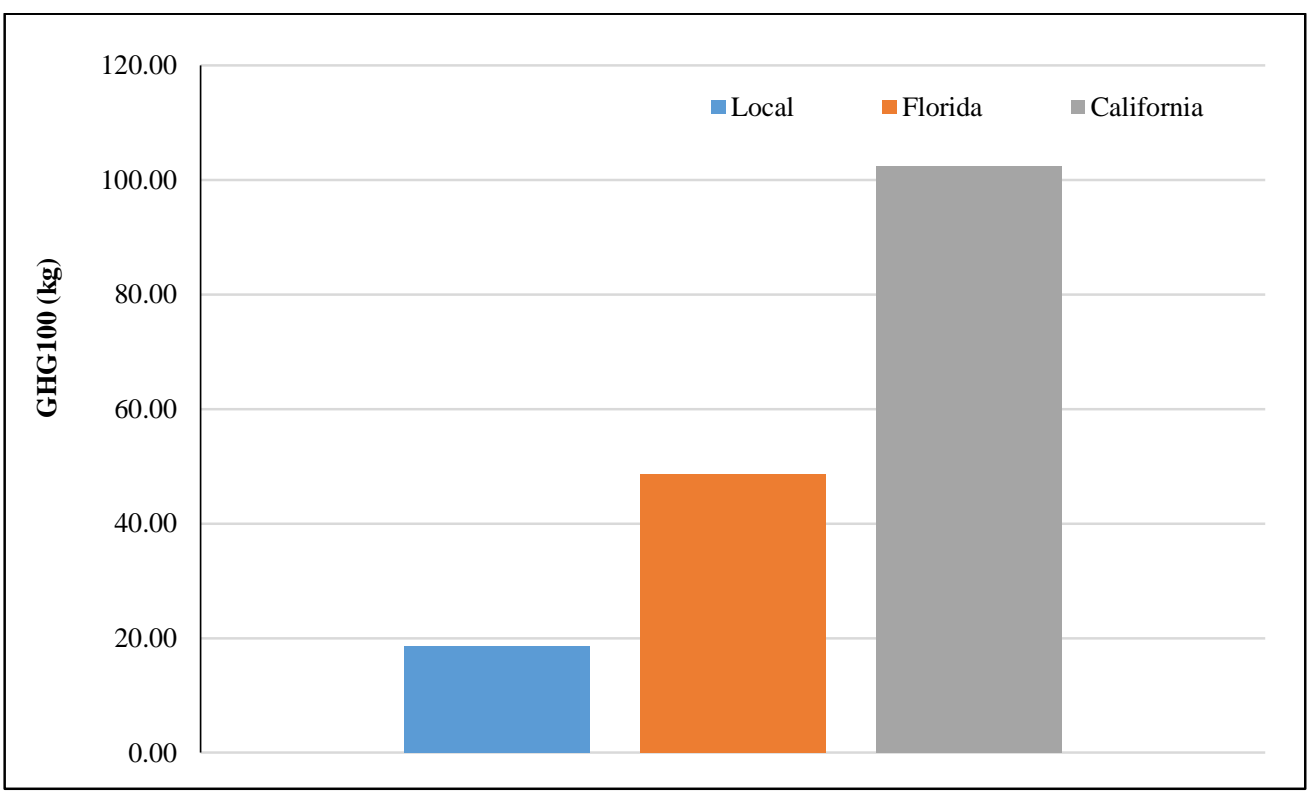

Figure 6. Overall GreenHouse Gas (GHG) emissions from strawberry production.

In September of 2015, XU dining service purchased 1,378 lbs. of tomatoes, 2,098 lbs. of lettuce, $990 \mathrm{lbs}$. of strawberries, and 61,091 lbs. of chicken, resulting in the total GWP emissions shown in Table 3. Figure 7 shows the total 
emissions as a result of these numbers and the proportion of those food items gotten from local sources mentioned previously. When non-local foods came from two separate areas the amount was simply halved since specific information on how much came from which state was unavailable. Nearly all of the differences in emissions come from transportation. As an example, if transportation was removed from the lettuce model, the emissions from production between local and California are the same, while Arizona has $\mathrm{CO}_{2}$ emissions $.96 \mathrm{~kg}$ higher and GHG100 emissions 1.17 $\mathrm{kg}$ higher per $100 \mathrm{~kg}$ of product. The increased use of chemicals for lettuce production in Arizona results in minimal increases in greenhouse gas emissions, which explains why the 370 fewer miles traveled to reach XU results in lower emissions for Arizona lettuce compared to California. The complete breakdown can be seen in Table 4. Overall, the emissions associated with production are very similar despite differences in chemical applications. As a result, emissions differences are due almost entirely to transportation.

Table 3. September GHG emissions in kg per product.

\begin{tabular}{cc}
\hline Tomato & 1,044 \\
Lettuce & 4,061 \\
Strawberries & 1,276 \\
Chicken & 266,111 \\
\hline
\end{tabular}

Table 4. Breakdown of GHG100 emissions $(\mathrm{kg})$ by product and region.

\begin{tabular}{c|cc|ccc|cccc}
\hline & \multicolumn{2}{|c|}{ Tomatoes } & \multicolumn{3}{c|}{ Lettuce } & \multicolumn{3}{c}{ Strawberries } \\
\cline { 2 - 9 } & Local & FL & Local & CA & AZ & Local & FL & CA \\
\hline Production & 19.21 & 19.7 & 19.68 & 19.68 & 20.85 & 18.11 & 19.5 & 18.11 \\
Transportation & 5.53 & 29.12 & 5.11 & 84.31 & 72.96 & 0.51 & 29.12 & 84.3 \\
\hline
\end{tabular}

Clearly emissions associated with local food acquisition are minimal compared to the emissions from getting food from other states, except in the case of tomatoes when over half of the produce comes from local sources. If $10 \%$ more of the three produce items were gotten from local sources, emissions would be reduced by $73 \mathrm{~kg}$ for tomatoes, $343 \mathrm{~kg}$ for lettuce, and $124 \mathrm{~kg}$ for strawberries. Since the dining service gets the least amount of lettuce from local sources and both non-local sources are on the other side of the country, there are of course the greatest savings to be had from getting more lettuce locally. While unrealistic, if all three of these produce items came entirely from local sources GWP would be reduced by 4,076 kg (compared to $540 \mathrm{~kg}$ from a 10\% increase in local food) for just one month. September through April are the busiest months for the dining service since school is in full session during these times. If the $10 \%$ increase in local food is applied to these eight months, total GWP for these three produce items would go from $51,048 \mathrm{~kg}$ to 46,728 , a decrease of over 4,000 kg. This decrease is based entirely on transportation, but could be offset if local production was done in greenhouses instead of open fields. Conversely, if the non-local production takes place in greenhouses a shift toward local production in fields would result in an even greater decrease in carbon emissions.

It is evident that emissions related to chicken outweighs that of produce due to both the significantly higher amount used and the moderately higher emissions associated per $100 \mathrm{~kg}$ of product. With only one known location for where $\mathrm{XU}$ gets chicken products there is no way to compare local and non-local numbers in this study. However, if that one location were $10 \%$ closer, meaning the chicken only traveled 198 miles instead of 220, GHG100 emissions for September would be lowered by nearly $7,000 \mathrm{~kg}$. Over the course of a school year this would result in a decrease in GHG100 emissions of approximately $55,500 \mathrm{~kg}$.

Results show lower carbon emissions associated with food production than the other LCAs cited in earlier chapters that included any form of transportation. For tomatoes, one Italian LCA showed $98.88 \mathrm{~kg} \mathrm{CO}_{2}$ equivalents per $100 \mathrm{~kg}$ of product, but included a cradle-to-grave study and is notably more detailed. A separate study that didn't include any post-production steps resulted in only $27.56 \mathrm{~kg}$ of $\mathrm{CO}_{2}$ equivalents per $100 \mathrm{~kg}[16,18]$. Local results from this study are very similar, but tomatoes from Florida fall somewhere between the two. Lettuce in the study comparing civic and industrial production showed emissions of 8 and $25 \mathrm{~kg}$ per $100 \mathrm{~kg}$ of civic lettuce and $32 \mathrm{~kg}$ per $100 \mathrm{~kg}$ of industrial lettuce [21]. This study also included transportation and local lettuce production numbers from this study match very closely. It is unclear how far the lettuce traveled in the study but based on the numbers it was likely grown much closer to the final destination. In a different study on lettuce, associated emissions totaled $566 \mathrm{~kg}$ per $100 \mathrm{~kg}$ of product and was again more inclusive, notably including storage, packaging, and distribution centers [20]. This same study looked at strawberries and showed $184 \mathrm{~kg}$ of $\mathrm{CO}_{2}$ equivalents per $100 \mathrm{~kg}$ of product [20]. A comparison of greenhouse and open field production of strawberries in Iran showed emissions of 77 and $65 \mathrm{~kg}$ of $\mathrm{CO}_{2}$ equivalents per $100 \mathrm{~kg}$ of product respectively, but did not take into account transportation or any other post-harvest processes [19]. The civic versus industrial study shows emissions from chicken production to be around 770 and $400 \mathrm{~kg} \mathrm{CO} 2$ equivalents per $100 \mathrm{~kg}$ of product for civic production and $260 \mathrm{~kg} \mathrm{CO}_{2}$ per $100 \mathrm{~kg}$ of industrial production (Hall et al. 2014). Another study of broiler chickens in Finland showed approximately $360 \mathrm{~kg}$ of $\mathrm{CO}_{2}$ equivalent emissions per $100 \mathrm{~kg}$ of product [22]. The 
GREET-based transportation model for chicken results confirm earlier assumptions that a lot of information regarding production was missing, as emissions are much lower than other studies. This model provided a comparison to produce items but lacks the detailed information needed for a more complete LCA.

Contrary to popular opinion in LCAs done on food production, transportation may play a larger role than is often assumed. The results from tomatoes, lettuce and potatoes in this study are comparable to others that have more thoroughly assessed the inputs needed for food production and accounted for the use of things like greenhouses and tractors for farming. Results from this study show that transportation is a large contributor to overall emissions in XU dining service's food acquisition.

This study does not factor in the proper use of fertilizers and associated impacts from potential runoff from excess fertilizer applications. The eutrophication and other effects of poor fertilizer practices are well beyond the scope of this study, but are another important factor to consider. In order to account for these effects, the farms and/or surrounding watersheds would have to be monitored regularly throughout the growing season, before and after fertilizer application(s).

Chicken production is shown to produce more emissions than any of the other foods. However, small scale local chicken production is not nearly as efficient as large-scale production and this study yielded results similar to those of Hall et al. which concluded local and small scale chicken production did not significantly reduce impacts based upon this analysis method [21]. The distance of 220 miles traveled for the majority of XU's egg and liquid egg needs is not very far compared to other transport for goods and is likely a much more efficient process than anything closer to campus. Even if there was an area on campus designated for raising chickens off of the dining hall waste, the footprint associated with housing structures and then transporting them away from campus for butchering and processing and back to campus for consumption would likely result in greater emissions than the current system. A more in depth study would need to be done in order to understand the emissions related to XU and its chicken consumption and where that process can be improved.

\section{4- Discussion of Results}

If NGOs become more interested in food products with lower carbon footprints, the effects could be seen at the market. Currently it can be difficult to find out where products come from based on the packaging. One solution to this problem would be making labels about where food comes from clearer and/or larger. Another alternative would be to lower the amount of foods in stores that aren't currently in season, thus decreasing shipments of food from far away. However, consumers would likely not be willing to give up their access to a wide variety of foods year round in an effort to lower carbon emissions. Simply making the consumers more aware of how far the food comes is therefore going to be preferred by a majority of consumers. This would also follow in the footsteps of organic products, of which the label on the package is the easiest way to learn about the product.

There are barriers to be overcome with regards to increasing the amount of locally grown food. The average age of farmers in America continues to rise and more land is being worked by fewer people. In essence, young people are not interested in being farmers [25]. As a result, fewer and fewer people live around these large mega farms so the food automatically has to travel further to get to the majority of consumers. Another problem for local food to overcome is its availability. An increase in local food production could provide benefits based upon the study by Coley et al. that looked at a home delivery system for food that resulted in lower emissions than consumer transportation to obtain food [12]. Although there are barriers to successful implementation of local food, they can be overcome with a little reworking of the food system and the role both farmers and consumers.

This study helped provide insight into emissions related to food transport. The amount of publicly available data regarding food inputs and transportation in the United States is severely lacking. Information regarding water usage and irrigation provided by the USDA is similarly difficult to discern. Similarly, the current complexity of the U.S. food chain makes it very difficult to monitor the path of specific food items from cradle to grave.

The LCA models have limitations. The GREET model used was appropriate for calculating transportation emissions but lacked the resources necessary in its databases for a proper assessment of any products other than those related to fuel. The wide range of results from LCAs across the world could demonstrate the variety of inputs and cultivation methods, but it could also reflect the variety of software capabilities used for conducting the study. The incongruences between software programs make studies difficult to compare with others and limit the scope of which the results can be applied to similar issues. Making more information available in combination with improvement in LCA software could lead to a rapid increase in understanding of food production and its associated emissions.

This study showed that even an abbreviated account of transportation can lead to fairly significant GHG emissions. Future analysis that incorporate distribution centers and storage into the food chain would provide additional insights on overall GHG emissions associated with university dining services. 
The overall emission savings from local food in this study are due mainly to the large amount of food consumed by XU dining services. Another direction to take further studies would be to look at the scale of food systems in which a change is deemed significant. Most likely, smaller restaurants that more often get all locally-sourced food, have a relatively small proportion of their emissions coming from the transportation of their food. In those cases most of the greenhouse gas emissions are likely coming from construction and operating of the building itself, similar to how construction of greenhouses caused more emissions than the food production going on inside them in the previously mentioned studies. Where local food makes the biggest difference is on large scales, such as college dining services and chain restaurants. This study looked at only three produce items and resulted in a decrease of over $4,000 \mathrm{~kg}$ of $\mathrm{CO}_{2}$ emissions during a school year by increasing the amount of locally-sourced food by $10 \%$. If that was applied to all, or even most, of the produce ingredients used by the school and applied to a majority of universities, the emissions reductions could become significant on a national scale.

Food choice and food waste also contribute substantially to the carbon footprint of food choices. Food waste contributes 1.4 kilograms $(\mathrm{kg})$ carbon dioxide equivalents $\left(\mathrm{CO}_{2}\right.$-eq) capita ${ }^{-1}$ day $^{-1}(28 \%)$ to the overall carbon footprint of the average U.S. diet. [31, 32] Whereas beef accounts for only $4 \%$ of the retail food supply by weight, it represents $36 \%$ of the diet-related GHG emissions. In addition to transportation issues with food, climate friendly food choices were proposed in Finland based upon a diet with less meat and less food waste and show a potential to reduce food related emissions by 0.3 to 0.5 million metric tons per year for the country $[33,34]$.

Overall the emissions associated with transportation of the tomatoes, lettuce, strawberries, and chicken for XU dining services are significant. Based on the large amount of chicken the school goes through, a more detailed LCA should be done in order to better understand the amount of emissions associated with it and how significant of savings can be had from local sources. The produce items, although smaller in scale, can also be substantial due to the variety of items. The emissions savings may be smaller per item but when combined still create a large difference.

\section{5- Conclusions}

This study compared GHG emissions from local and non-local food production. The results show similarities with other reports in the literature. The main takeaways from the study are as follows:

- Carbon emissions associated with food from local produce sources are lower than non-local sources according to this GREET-based transportation model. Purchasing these foods from local sources could significantly reduce fruit and vegetable impacts. The impact reductions associated with locally sourced chicken were less substantial.

- The amount of publicly available data regarding crop cultivation makes life cycle assessments difficult to complete.

- The scale of University food purchasing operations created significant impact reductions for locally sourced food due to the quantity of food purchased.

\section{6- Acknowledgements}

The authors would like to express their gratitude to the Environmental Resource Management Program, a joint venture between the University of Malta and James Madison University for providing supporting advising and critique for this research.

\section{7- Conflict of Interest}

The authors declare no conflict of interest.

\section{8- References}

[1] Ivanova, Diana, Konstantin Stadler, Kjartan Steen-Olsen, Richard Wood, Gibran Vita, Arnold Tukker, and Edgar G. Hertwich. “Environmental Impact Assessment of Household Consumption.” Journal of Industrial Ecology 20, no. 3 (December 18, 2015): 526-536. doi:10.1111/jiec.12371.

[2] Food Service Technology Center (2016). Available online: http://www.fishnick.com/about/overview/ (accessed on 1 March 2019).

[3] Green Restaurant Association (2016). Available online: https://www.dinegreen.com/certification-standards (accessed on 21 April 2019).

[4] U.S. Department of Agriculture (2015). Agricultural marketing services's national organic program. Available online: https://www.ams.usda.gov/publications/content/about-national-organic-program (accessed on 17 March 2019).

[5] Food Alliance (2016). Available online: http://foodalliance.org/certification (accessed on 19 April 2019).

[6] Fair Trade USA (2016). Available online: http://www.fairtradeusa.org/what-is-fair-trade (accessed on 17 March 2019).

[7] Rainforest Alliance (2016). Available online: http://www.rainforest-alliance.org/about (accessed on 17 March 2019). 
[8] Humane Farm Animal Care (2014). Program/policy manual. Available online: http://certifiedhumane.org/how-we-work/ourstandards/ (accessed on 17 March 2019).

[9] Animal Welfare Approved (2013). Available online: http://animalwelfareapproved.org/about/ (accessed on 19 April 2019).

[10] Salmon Safe (2015). Available online: http://www.salmonsafe.org/about (accessed on 23 July 2019).

[11] Protected Harvest (2009). Available online: http://www.protectedharvest.org/?page_id=134 (accessed on 25 March 2019).

[12] Coley, David, Mark Howard, and Michael Winter. "Local Food, Food Miles and Carbon Emissions: A Comparison of Farm Shop and Mass Distribution Approaches.” Food Policy 34, no. 2 (April 2009): 150-155. doi:10.1016/j.foodpol.2008.11.001.

[13] Argonne National Laboratory (2015). Energy systems. Available online: https://greet.es.anl.gov/index.php (accessed on 26 March 2019).

[14] Leach, Allison M., James N. Galloway, Elizabeth A. Castner, Jennifer Andrews, Neil Leary, and John D. Aber. “An Integrated Tool for Calculating and Reducing Institution Carbon and Nitrogen Footprints.” Sustainability: The Journal of Record 10, no. 2 (April 2017): 140-148. doi:10.1089/sus.2017.29092.aml.

[15] Paul, B.K., R. Frelat, C. Birnholz, C. Ebong, A. Gahigi, J.C.J. Groot, M. Herrero, et al. "Agricultural Intensification Scenarios, Household Food Availability and Greenhouse Gas Emissions in Rwanda: Ex-Ante Impacts and Trade-Offs." Agricultural Systems 163 (June 2018): 16-26. doi:10.1016/j.agsy.2017.02.007.

[16] Torrellas, Marta, Assumpció Antón, Juan Carlos López, Esteban José Baeza, Jerónimo Pérez Parra, Pere Muñoz, and Juan Ignacio Montero. "LCA of a Tomato Crop in a Multi-Tunnel Greenhouse in Almeria." The International Journal of Life Cycle Assessment 17, no. 7 (June 1, 2012): 863-875. doi:10.1007/s11367-012-0409-8.

[17] Roy, Poritosh, Daisuke Nei, Hiroshi Okadome, Nobutaka Nakamura, Takahiro Orikasa, and Takeo Shiina. "Life Cycle Inventory Analysis of Fresh Tomato Distribution Systems in Japan Considering the Quality Aspect.” Journal of Food Engineering 86, no. 2 (May 2008): 225-233. doi:10.1016/j.jfoodeng.2007.09.033.

[18] Cellura, Maurizio, Sonia Longo, and Marina Mistretta. "Life Cycle Assessment (LCA) of Protected Crops: An Italian Case Study.” Journal of Cleaner Production 28 (June 2012): 56-62. doi:10.1016/j.jclepro.2011.10.021.

[19] Khoshnevisan, Benyamin, Shahin Rafiee, and Hossein Mousazadeh. "Environmental Impact Assessment of Open Field and Greenhouse Strawberry Production.” European Journal of Agronomy 50 (October 2013): 29-37. doi:10.1016/j.eja.2013.05.003.

[20] Gunady, Maria G.A., Wahidul Biswas, Vicky A. Solah, and Anthony P. James. "Evaluating the Global Warming Potential of the Fresh Produce Supply Chain for Strawberries, Romaine/cos Lettuces (Lactuca Sativa), and Button Mushrooms (Agaricus Bisporus) in Western Australia Using Life Cycle Assessment (LCA).” Journal of Cleaner Production 28 (June 2012): 81-87. doi:10.1016/j.jclepro.2011.12.031.

[21] Hall, Gillian, Alison Rothwell, Tim Grant, Bronwyn Isaacs, Laura Ford, Jane Dixon, Martyn Kirk, and Sharon Friel. "Potential Environmental and Population Health Impacts of Local Urban Food Systems under Climate Change: a Life Cycle Analysis Case Study of Lettuce and Chicken.” Agriculture \& Food Security 3, no. 1 (2014): 6. doi:10.1186/2048-7010-3-6.

[22] Katajajuuri, Juha-Matti. "Experiences and improvement possibilities-LCA case study of broiler chicken production." In 3rd International Conference on Life Cycle Management, Zurich, Switzerland, pp. 27-29. 2007.

[23] Pirog, R.S., Van Pelt, T., Enshayan, K., \& Cook, E.; Food, fuel, and freeways: An Iowa perspective on how far food travels, fuel usage, and greenhouse gas emissions. Leopold Center Pubs and Papers. Paper 3 (2001). Available online: http://lib.dr.iastate.edu/leopold_pubspapers/3 (accessed on 23 July 2019).

[24] United States Department of Agriculture (2018). Farm Demographics 2018. Available online: http://www.start2farm.gov/usda /knowledge (Accessed on 30 October 2018).

[25] U.S. Department of Agriculture, Economic Research Service (2010). U.S. tomato statistics (92010).

[26] U.S. Department of Agriculture, Economic Research Service (2011). U.S. lettuce statistics 2011.

[27] U.S. Department of Agriculture, Economic Research Service (2013). U.S. strawberry industry (95003).

[28] Geisseler D. and Horwath W.R. (2013). Lettuce production in California. Fertilizer Research and Education Program.

[29] Climate Central (2014). New CO2 milestone: 3 months above 400 ppm. Available online: http://www.climatecentral.org/news/co2-milestone-400-ppm-climate-17692 (accessed on 07 April 2019).

[30] Environmental Protection Agency (2016). Understanding global warming potentials. Available online: https://www3.epa.gov/climatechange/ghgemissions/gwps.html (accessed on 07 April 2019).

[31] Papargyropoulou, Effie, Rodrigo Lozano, Julia K. Steinberger, Nigel Wright, and Zaini bin Ujang. “The Food Waste Hierarchy as a Framework for the Management of Food Surplus and Food Waste." Journal of Cleaner Production 76 (August 2014): 106115. doi:10.1016/j.jclepro.2014.04.020. 
[32] Nissinen, Ari, Eva Heiskanen, Adriaan Perrels, Elina Berghäll, Virpi Liesimaa, and Maija K. Mattinen. "Combinations of Policy Instruments to Decrease the Climate Impacts of Housing, Passenger Transport and Food in Finland.” Journal of Cleaner Production 107 (November 2015): 455-466. doi:10.1016/j.jclepro.2014.08.095.

[33] Behrens, Paul, Jessica C. Kiefte-de Jong, Thijs Bosker, João F. D. Rodrigues, Arjan de Koning, and Arnold Tukker. "Evaluating the Environmental Impacts of Dietary Recommendations." Proceedings of the National Academy of Sciences 114, no. 51 (December 4, 2017): 13412-13417. doi:10.1073/pnas.1711889114.

[34] Heller, Martin C., and Gregory A. Keoleian. "Greenhouse Gas Emission Estimates of U.S. Dietary Choices and Food Loss." Journal of Industrial Ecology 19, no. 3 (September 4, 2014): 391-401. doi:10.1111/jiec.12174. 